\title{
EDITORIAL
}

DOI: $10.2965 / 25944630432020007$

\section{Educação e design participativo}

Profa. Dra. Maria Carolina Garcia ${ }^{1}$

Loeb Fellow 2019 Michael Smith Masis²

Prof. Dra. Alexandra Cabral ${ }^{3}$

Em Cem anos de solidão, o escritor colombiano Gabriel García Márquez descreve uma peste que surge e cresce em espiral desgovernada. Nesse romance, a estranha epidemia prolifera absurdamente até contaminar todos os moradores de Macondo, um vilarejo até então adormecido nos confins da América Latina (GARCÍA MÁRQUEZ, 2005, p. 47-54). Seus cidadãos mobilizam-se em equipe para enfrentar a crise decorrente do prolongamento da situação, até inaugurar uma nova etapa civilizatória, não sem antes chacoalhar de forma desestabilizadora tanto o cotidiano individual quanto a atmosfera social. Mera coincidência ou uma lição para levar em conta?

Na natureza, todos os elementos estão conectados. De maneira inequívoca, essa premissa ecoa no tempo lento e contemplativo resultante da pandemia do Novo Coronavírus. Este, por sua vez, inaugura a ideia de um pós-presente, pautado pelo conceito de Multiverso. Sem fronteiras espaciais, o Multiverso opõe-se à ideia totalitária e soberana de Universo, optando por ratificar a importância de uma cidadania global, sem fronteiras, pautada pela sintonia entre a natureza humana e seu entorno e as múltiplas vidas que se sobrepõem em ambientes físicos e digitais. As distâncias já não se medem em quilômetros, mas em fusos horários. Ações ao vivo, mediadas pela tecnologia, proliferam mundo afora, permitindo que as pessoas encontrem novas formas de convívio e outras possibilidades de vinculação.

Em 31 de março de 2020, começaram a circular em ambiente online e-books concentrando reflexões de grandes pensadores, como a Sopa de Wuhan, capitaneada por estudiosos como Giorgio Agamben e Slavov Zizek. Em 2 de abril do mesmo ano, a revista Deezen,

\footnotetext{
${ }^{1}$ Centro Universitário Belas Artes de São Paulo - Programa de Pós-Graduação em Arquitetura, Urbanismo e Design - Grupo de Estudos Design e Convergência ${ }^{2}$ Harvard University - Graduate School of Design

3 Universidade de Lisboa - Faculdade de Arquitetura
} 
umas da mais importantes no mundo da arquitetura e do design, anunciou seu primeiro Virtual Design Festival. No mundo da música e do entretenimento, Lady Gaga tornou-se curadora da iniciativa One World - Together at Home, que, em 18 de abril de 2020, sob iniciativa da Organização Mundial de Saúde e do movimento Global Citizen, promoveu um festival musical transmitido globalmente em prol dos profissionais de saúde. Em A Cruel Pedagogia do Vírus, outra obra surgida em meio à pandemia e viralizada por meio das mídias sociais digitais, o estudioso português Boaventura Sousa Santos observa:

"A ideia conservadora de que não há alternativa ao modo de vida imposto pelo hiper-
capitalismo em que vivemos cai por terra. Mostra-se que só não há alternativas porque
o sistema político democrático foi levado a deixar de discutir as alternativas" (SANTOS,
2020).

O dossiê que você tem em mãos busca justamente discutir alternativas que visualizem a participação coletiva no enfrentamento de questões comunitárias. Entendemos o design participativo como mecanismo de longo alcance e impacto escalável na educação, convertendo-se numa prática sustentável de mudanças sociais, tecnológicas e políticas. Diante de um evento tão inesperado quanto devastador como a pandemia global do Novo Coronavírus, a cooperação revela-se urgente nesta jornada de aprendizagem.

Se Meadows (2008) considera que a linguagem é um soft skill fundamental para que o design possa se converter em instrumento de transformação social, neste contexto em particular, o entendimento é condição sine qua non, conforme discutido por Tadeu Rodrigues luama e Jorge Miklos em Design de uma proposta participativa comunicacional, artigo que elucida o panorama teórico que abrange este dossiê. É por meio da linguagem que construímos o entendimento e permitimos que se estabeleça a empatia necessária para que o designer possa se concentrar no briefing de cada projeto, como destacam os autores em sua proposição. A abordagem dos pesquisadores avalia ainda o contexto tecnológico e os estratagemas gerados pela pandemia do Novo Coronavírus em termos de comunicação, didática e cultura, levando em consideração as premissas do design participativo.

Para Santos (2020), a pandemia cria “(...) uma consciência de comunhão planetária, de algum modo democrática. A etimologia do termo pandemia diz isso mesmo: todo o povo". Se o engajamento e a participação convertem-se numa ferramenta indispensável para romper os efeitos do isolamento social, sobretudo com respeito à saúde física e mental, tanto quanto em termos do desenvolvimento, social e econômico, o compartilhamento e a abertura às esferas coletivas tornam-se companheiros inseparáveis. Neste sentido, a experiência relatada pelos arquitetos Oscar Aceves, Oscar Rodríguez, Gustavo Sosa, Jesús Belmonte, Karlys Pulido e Enrique Girán em Caracas vinculada, cidade hospital apresenta o potencial do espaço urbano para promover vinculações e encontros, por meio da observação das conexões existentes entre os cidadãos, a cidade e a natureza do bairro popular Santa Rosa, em Caracas, Venezuela. Entendemos precisamente que profissionais conscientes de seu papel como vinculadores podem exercer um papel-chave no desenvolvimento de processos centrados na interação humana, co-criando estratégias e ações abrangentes e inclusivas de educação: 
outrora por vezes imperceptíveis e, no pós-presente, ansiosamente desejadas. Essa relação torna-se palpável no relato dos autores sobre as ruas da capital venezuelana, quando readequadas para promover essa potencialidade, considerando sobretudo que o espaço urbano se oferece como cenário adequado a essa premissa e há que se mobilizar distintos atores para que as mudanças se estabeleçam. Conforme explicita o artigo em questão, acupunturas urbanas de ação instantânea, fundamentadas na promoção de empoderamento comunitário, apresentam engajamentos educativos de longo prazo, incluindo comunidades heterogêneas e sistemas mais amplos de transformação.

Pesquisas em educação e design participativo guiadas por processos de aprendizagem compartilhada, cujo estímulo contínuo sugere um movimento de lifelong learning, contrário ao ensino cartesiano e pré-configurado, destacam especialmente práticas educacionais em design voltadas ao entendimento, análise e, inclusive, apropriação e adaptação a outros contextos. Essas atividades nem sempre se restringem à sala de aula, utilizando o corpo e as camadas que se sobrepõem a ele como ponto de partida para o entendimento também em oficinas e cursos de curta duração em distintos formatos, para espaços físicos e digitais. O trabalho colaborativo e transdisciplinar está na essência do design, particularmente na área de moda, entendida como modo de vida. Projetos exitosos consolidam-se ao longo do tempo quando permitem um processo de intensa colaboração e aprendizagem comunitária, guiada por principios de compartilhamento. Isso inclui os modos pelos quais os usuários avaliam, adaptam e integram conhecimentos compartilhados por outros atores ao seu contexto e práticas cotidianas, como relatam Maira Pereira Gouveia Coelho e Juliana Rocha Franco em Oficina O Casaco de Marx, artigo produzido a partir de atividade homônima idealizada pela primeira autora a partir de obra de Peter Stalybrass (2012), base teórica referencial bastante presente no cenário brasileiro de estudos da moda. As pesquisadoras promovem uma visão educativa cosmopolita que começa no conhecimento do próprio entorno e que se constrói nas práticas locais, cotidianas e familiares no diálogo com a jornada dos produtos de moda, com resultados promissores em termos da aplicação do design participativo como estratégia de engajamento. A realização da oficina em contextos diferentes nos leva a refletir sobre o imenso potencial de aprendizado colaborativo.

Especialmente para aqueles que projetam experiências educativas, o design de experiências participativas dessa natureza revela-se um aliado na construção, coletiva, de distintos meios de difundir o conhecimento e minimizar a exclusão. Perceber o Outro e interagir com ele, não obstante eventuais distâncias de fusos horários, geolocalização ou navegação social, constituem uma forma poderosa de recriar o pós-presente que desejamos. O que podemos aprender, auxiliados por ações prévias em que a participação coletiva assume protagonismo? Luisa Mendes Tavares nos fala desse potencial latente no artigo O outro no projeto de design, quando analisa disciplinas do Bacharelado em Design de Moda cujo projeto é realizado a partir do encontro com pessoas que não são da área, no escopo da percepção de que o design é um campo interdisciplinar em que a representatividade de múltiplas vozes é vital. 
Na mesma linha de raciocínio, a aplicação de métodos de co-design para incentivar o desenvolvimento de práticas sustentáveis na educação em design de moda é precisamente o foco de "Co-designing with sustainable practices in fashion design teaching", artigo que discute o processo de design e desenvolvimento de produtos, mediante o envolvimento de diversos atores e organizações sociais. Não obstante os acontecimentos sem precedentes que vivemos em 2020, nota-se que a humanidade encontra forças na arte, na criatividade e na natureza para superar e se recuperar. Justamente, ao enfrentar os desafios físicos e mentais de um ambiente inteiramente novo, comunidades ao redor do mundo estão sentido a necessidade de manter e melhor as conexões e vínculos entre si. Há muito que descobrir quando observamos como a natureza vem inovando ao longo do tempo para dar suporte a comunidades de todos os tamanhos e formatos, conectando seus membros com sujeitos de habilidades complementares, para dividir o trabalho e compartilhar o conhecimento em distintos modelos de liderança, cooperação e estruturação.

Esse dossiê convida você a refletir sobre o design centrado na vida e focado em inovação responsável, capaz de engajar distintos públicos a darem sua contribuição em projetos de bem-estar coletivo. Esperamos que possa fomentar novas ações educativas em rede e que também elas se multipliquem, marcando uma era de convívio pleno e exercício consciente do design, para promover a convergência de esforços em torno de um melhor viver neste Multiverso de possibilidades.

\section{Referências:}

MEADOWS, Donella. Thinking in Systems. London: Sustainability Institute, 2008.

SANTOS, Boaventura de Sousa. A Cruel Pedagogia do Vírus. Coimbra: Edições Almedina., 2020 (e-book). 